\title{
WATER RENEWAL TIME AND TRACE METAL CONCENTRATION IN CIVITAVECCHIA PORT (ROME), ITALY
}

\author{
SIMONE BONAMANO ${ }^{1}$, DANIELE PIAZZOLLA ${ }^{1}$, ALICE MADONIA ${ }^{1}$, FRANCESCO PALADINI DE \\ MENDOZA $^{1}$, VIVIANA PIERMATTEI ${ }^{1}$, SERGIO SCANU ${ }^{1}$, MARCO MARCELLI $^{1}$ \& GIUSEPPE ZAPPALÀ ${ }^{2}$ \\ ${ }^{1}$ DEB Experimental Oceanology and Marine Ecology Laboratory, Tuscia University, Viterbo, Italy \\ ${ }^{2}$ Istituto per l'Ambiente Marino Costiero (IAMC), National Research Council, Messina, Italy
}

\begin{abstract}
Most of the harbours can be considered as semi-enclosed areas where water stagnation leads to physical and chemical alterations due to anthropogenic activities. These features affect the quality of the port waters as well as the environmental health of coastal ecosystems in the surrounding areas. In order to understand the potential degradation of water quality within the harbour area it is essential to evaluate the hydrodynamic behaviour of the system. In this study, the DELFT3D-FLOW model, which allows to estimate the three-dimensional field velocity, was used to spatially characterize the water renewal time within the harbour. In particular, the flushing time (FT), which represents the time required for the total mass of a conservative tracer originally within the water body to be reduced to a factor $1 / e$, was examined. The concentration of contaminants in sediments is indeed a proper parameter to test the reliability of the calculated water renewal time within the semi-enclosed basins, since it relies on time-integrated measurements compared to single observations of water column. This research aims at studying the relation between the FT and the pollution due to trace metals in marine sediments. For this purpose, surface sediment samples were collected along a series of stations located in the innermost part and near the mouth of the Civitavecchia harbour. As, $\mathrm{Cr}, \mathrm{Hg}, \mathrm{Ni}, \mathrm{Cu}, \mathrm{Zn}, \mathrm{Pb}$ and $\mathrm{Al}$ concentrations were analysed to calculate the enrichment factor, which provides an estimate of the heavy metal contamination in the harbour surface sediment. The obtained results show a high correlation between the FT and the enrichment factor within the Civitavecchia port, confirming that water renewal can be used as an indicator of water quality degradation in semi-enclosed areas.

Keywords: Civitavecchia harbour, enrichment factor, flushing time, trace metal contamination
\end{abstract}

\section{INTRODUCTION}

Harbour basins are considered semi-enclosed areas and, as such, can be affected by water quality degradation [1] and high contamination levels of marine sediments [2]. The maintenance or achievement of Good Ecological Potential (GEP), as prescribed by the Water Framework Directive (Council Directive 2000/60/EC), cannot be obtained without the knowledge of hydrodynamic behaviour of port areas. The water circulation within lagoons, lakes and semi-enclosed areas (e.g. harbours) is analysed by many authors through the use of hydrodynamical models [3-7]. The model results are then used to calculate the hydrodynamic time parameters (age, flushing time (FT), residence time, transit time and turnover time) that are considered synthetic indicators to relate the dynamic processes with contaminant distribution in marine environment and consequently with the health status of aquatic ecosystems [3]. The hydrodynamic time parameter chosen in this study is FT, which is defined as the time taken by a conservative tracer within the water body to be reduced to a factor of 1/e [8].

Among the chemical and biological data, the concentration of contaminants in marine sediments is probably the most representative parameter to evaluate the effects of water renewal within the semi-enclosed areas as it gives a time-integrated measurement of chemical concentration over the whole exposure time, instead of an unrepresentative single measurement [9-11]. The enrichment degree of contaminants in sediments can be assessed using different 
contamination indices. The enrichment factor (EF) [12] is one of the more widely used to determine the possible anthropogenic impacts in the semi-enclosed areas [13, 14].

Correlations between biological and chemical data and hydrological time parameters are shown by many authors [5, 15-17], even if few studies focus on harbour areas [2, 18]. Montero et al. [18] showed that the metal contamination gradient is in accordance with the residence time calculated within the Pasaia harbour (Spain) and along the channel of the estuary. Recently, an interesting relation was found within the Bari port basin (Italy) between the bottom shear stress, selected as an indicator of the effects of marine currents and the hazard assessment indexes such as cNWAC and mERMq [2].

In the present study, EF was used as a tool to investigate the correlation between the trace metal concentrations in harbour sediments and the hydrodynamic time parameters properly selected and strictly connected to water circulation in semi-enclosed areas, that is FT.

\section{MATERIALS AND METHODS}

This research integrates the use of observing systems, mathematical models and sediment samplings, as better depicted in subsequent paragraphs.

\subsection{The study area}

The Civitavecchia harbour is located on the west coast of Central Italy (Western Mediterranean Sea), not far from Rome (about $80 \mathrm{~km}$ ) and for this reason it is also known as the port of Rome. Thanks to this strategic position and the realization of new piers and docks; in the last years, it has become the leader of cruise traffic in the Mediterranean recording 2.6 million tourists in 2011 (data provided by booking and turnaround). Currently, the harbour basin extends on $1.62 \mathrm{~km}^{2}$ with an average depth of $15 \mathrm{~m}$ (Fig. 1). The water exchange between the inner and outside areas of the port is regulated by the only entrance located in the northern zone, making the southern part of the harbour basin more subject to high water renewal time caused by low currents velocity $[19,20]$. To address this problem, a new south mouth will be created in the following years to ensure an efficient renewal of harbour waters.

The enlargement works of Civitavecchia port performed in the recent years stimulated the development of the Civitavecchia Coastal Environment Monitoring System (C-CEMS) [21] to evaluate the potential effects of dredged materials on coastal ecosystems around the Civitavecchia harbour. These ecosystems are included in two marine protected areas (Site of Community Importance) established to protect the habitats (Posidonia oceanica and reefs of rocky substrates and biogenic concretions) and species (Pinna nobilis and Corallium rubrum) enclosed in attachments 1 and 2 of EU Directive 92/43/EEC.

\subsection{FT estimation}

The hydrodynamic time parameter chosen in this study is the FT, which is computed by simulating the transport and diffusion processes of a conservative tracer released uniformly within the Civitavecchia harbour with a concentration corresponding to 1 . The reduction of the tracer concentration is due to the water exchange between the source area and the outer domain, where the concentration was set to 0 . The FT $(t)$ as stated in eqn (1) is obtained [8]:

$$
C(t)=C_{0} \cdot e^{-t / T_{f}}
$$




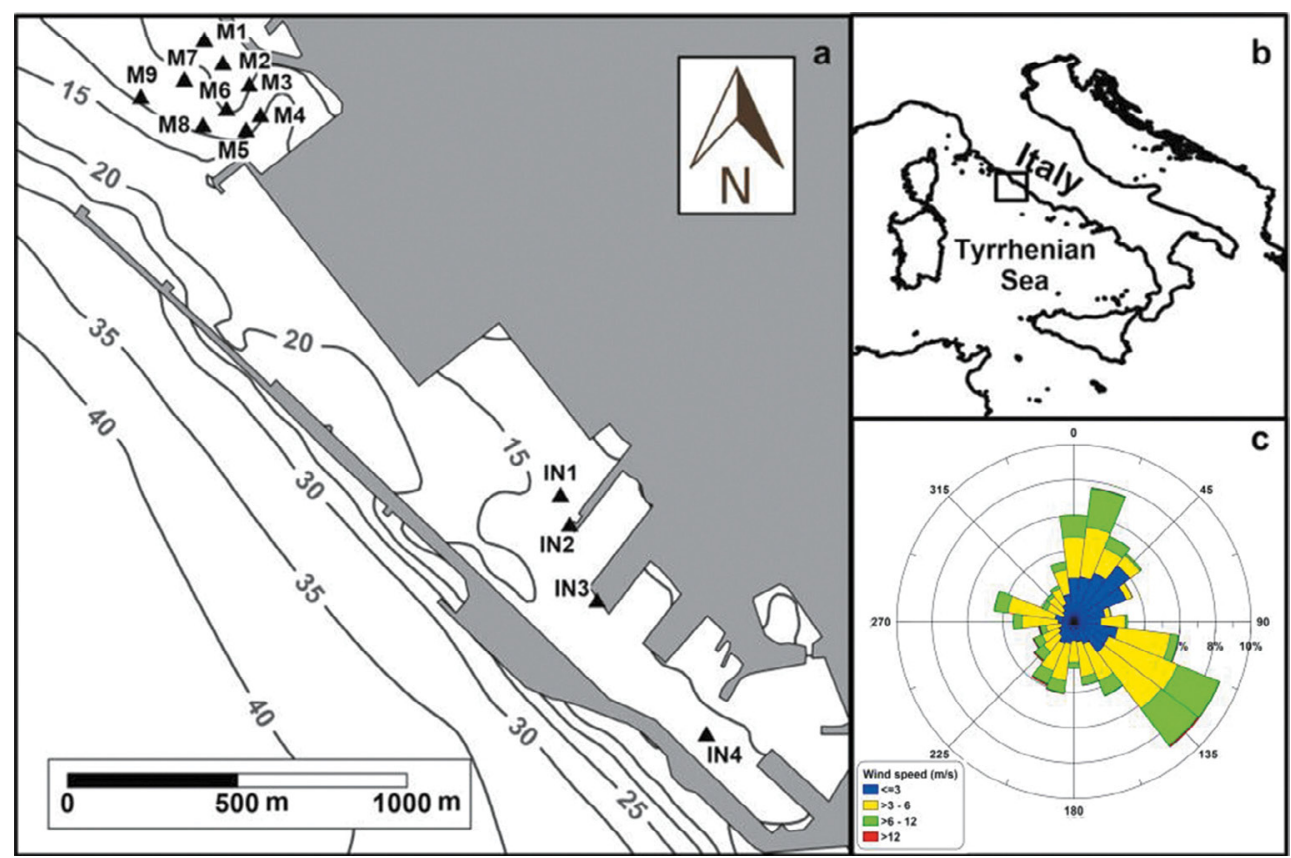

Figure 1: Study area with the sampling points of marine sediments (a) and its location along the north-eastern Tyrrhenian coast of Italy (b). Wind rose obtained by weather station data of C-CEMS (c).

where $C_{0}$ is the initial conservative tracer concentration, $C(t)$ is the concentration value reduced by $37 \%$ and $T_{f}$ is $1 / e$.

In this study, DELFT3D-FLOW [22] is used to calculate the diffusion and transport of a passive tracer in Civitavecchia harbour zone. It allows to simulate non-steady and transport phenomena induced by tidal and meteorological forcing on a curvilinear grid.

This grid type reduces the computational effort as it allows to obtain a higher resolution inside the harbour basin and a lower resolution in the other parts of the computational domain. Within the port area the mesh consists of 210 grid points in the along-shore direction and 48 grid points in the cross-shore direction with a $15 \mathrm{~m}$ grid resolution.

The study area is located in the centre of the model domain to avoid small errors that may occur near the boundaries. To ensure that the solution of the mathematical boundary value problem is well posed, Neumann boundary conditions were applied on the cross-shore boundaries in combination with a water-level boundary on the seaward side. Free-slip condition is assigned at the closed coastal boundaries. To analyse the transport of a passive tracer within the harbour basin, the horizontal diffusion coefficient equal to $0.05 \mathrm{~m}^{2} / \mathrm{s}$, as reported by Riddle and Lewis [23] and Jounon et al. [3], is used. The same model implementation was used by Bonamano et al. [21] to analyse the water circulation along the Civitavecchia coastal zone. In that work, the comparison between DELFT3D-FLOW model outputs and Acoustic Doppler Profiler (ADP) current measurements has shown a good agreement.

In this study, idealized and real scenarios are reproduced using the data acquired by the C-CEMS weather station. In the idealized scenarios, the wind directions are selected equal 
Table 1: Summary of computational scenarios.

\begin{tabular}{llc}
\hline Scenario & \multicolumn{2}{c}{ Wind forcing } \\
\hline & Speed $(\mathrm{m} / \mathrm{s})$ & Direction $\left({ }^{\circ} \mathrm{N}\right)$ \\
\hline I-SE & 6.67 & 130 \\
I-NE & 6.1 & 10 \\
I-SW & 4.75 & 200 \\
R1 & From 22 November 2008 \\
& to 2 December 2008 \\
R2 & From 17 December 2008 \\
& to 28 December 2008 \\
\hline
\end{tabular}

Note: I, idealized; R, real.

to the more frequent for the three sectors of SE, NE and SW (Fig. 1c). For each of the three sectors, wind speed was chosen with an exceedance frequency of about 100 days per year, in order to reproduce the water circulation that frequently occurs [6]. To evaluate the hydrodynamic field induced by variable wind conditions, we have selected two periods (R1 and R2) at the end of 2008, in coincidence with the sampling of marine sediments in the harbour basin.

R1 period (scenario R1) lasts from 22 November to 2 December including four wind gusts with the intensity between 12 and $16 \mathrm{~m} / \mathrm{s}$ coming from southern sectors (top-left corner of Fig. 3).

R2 period (scenario R2) lasts from 17 December to 28 December and is characterized by mild winds except for two moderate storms (about $8 \mathrm{~m} / \mathrm{s}$ ) coming from northern quadrants (top-left corner of Fig. 3).

All the simulated scenarios are synthesized in Table 1.

All of the simulations proposed in this work were carried out using a time step of $60 \mathrm{~s}$, which is sufficient to meet the Courant condition.

\subsection{Sediment sampling and analysis}

To evaluate the possible relationship between FT and trace metal pollution status, surface sediment was collected at 13 sampling stations within the Civitavecchia harbour in 2008.

The surface layer $(1 \mathrm{~cm})$ of each sample was subsampled, homogenized and transported to the laboratory at $4^{\circ} \mathrm{C}$ using polyethylene bags.

$\mathrm{As}, \mathrm{Cr}, \mathrm{Hg}, \mathrm{Ni}, \mathrm{Cu}, \mathrm{Zn}, \mathrm{Pb}$ and $\mathrm{Al}$ extraction from surface sediments was performed following EPA 3051A:2007 and 6020A:2007 methods, respectively. In particular, $1 \mathrm{~g}$ of sediment samples was weighed with an analytical scale and mineralized in a microwave system with a digestion solution prepared using $9 \mathrm{~mL}$ of $65 \% \mathrm{HNO}_{3}$ and $3 \mathrm{~mL}$ of $30 \% \mathrm{HCl}$. Finally, analytical determination of metals was performed using inductively coupled plasma mass spectrometry.

In order to evaluate the enrichment degree of the selected trace metals, $\mathrm{EF}[12,24]$ was used. For EF calculation, trace metal concentrations were normalized using a sample reference metal (such as $\mathrm{Fe}$ or $\mathrm{Al}$ ). $\mathrm{Fe}$ and $\mathrm{Al}$ are considered as 'proxy' for the clay content $[25,26]$. In this study, Al concentrations were used for the normalization of trace metals as described by Woitke et al. [27]. The EF is expressed as 


$$
\mathrm{EF}=\frac{\left(\frac{\mathrm{Me}}{\mathrm{Al}}\right)_{\text {Sample }}}{\left(\frac{\mathrm{Me}}{\mathrm{Al}}\right)_{\text {Background }}}
$$

where $(\mathrm{Me} / \mathrm{Al})_{\text {Sample }}$ is the metal to $\mathrm{Al}$ ratio in samples of interest; $(\mathrm{Me} / \mathrm{Al})_{\text {Background }}$ is the natural background value of metal to $\mathrm{Al}$ ratio [28].

In the absence of data relating to the local trace metal background values, this study uses those reported for the continental shale [29]. Sakan et al. [30] suggested that EF values $<1$ indicate no enrichment; $<3$ indicate minor enrichment; $3-5$ indicate moderate enrichment; 5-10 indicate moderately severe enrichment; $10-25$ indicate severe enrichment; $25-50$ indicate very severe enrichment; and $>50$ indicate extremely severe enrichment. In order to get insights into possible inter-dependence between the hydrodynamic conditions (in terms of FT) and the trace metal EF values, a Pearson's correlation analysis was performed.

\section{RESULTS}

In this section, FT distribution induced by idealized and real weather conditions as well as the trace metal contamination levels in the harbour sediments are reported. Finally, the comparison between the water renewal time and enrichment degree of contaminants in marine sediments is evaluated.

\subsection{FT distribution}

The maps represented in Figs 2 and 3 show a time renewal gradient between the innermost zone of Civitavecchia port and the northern entrance. In I-SW and I-SE scenarios, FT values are greater than $220 \mathrm{~h}$ (about 9 days) in the southern area of harbour basin.

In the central part of the port, the two conditions show a slight discrepancy as the water renewal time is about $100 \mathrm{~h}$ for I-SW and $130 \mathrm{~h}$ for I-SE. This difference is partly due to the lower wind intensity of SW scenarios that generates a limited water circulation in the inner part of the harbour basin. On the contrary, I-NE condition induces high currents velocity in the Civitavecchia port, stimulating a better efficiency in the water renewal with respect to the other two scenarios. In this case, FT values are, respectively, about 100 and $40 \mathrm{~h}$ in the innermost and central part of the basin.

The real scenario characterized by high wind intensity (R1) highlights water renewal time greater than $140 \mathrm{~h}$ in the southern zone and $70 \mathrm{~h}$ in the central part of Civitavecchia port. Otherwise, when the weather conditions are less intense (R2), FT shows a slight increase with values of 170 and $80 \mathrm{~h}$ in the innermost and central part of the harbour basin, respectively.

In all simulated scenarios, FT has low values in the northern zone of Civitavecchia port $(<10 \mathrm{~h})$ because the harbour entrance allows a rapid exchange between the harbour and outside waters.

\subsection{Trace metals enrichment in harbour sediments}

The calculated $\mathrm{EF}$ values follow this order: $\mathrm{As}>\mathrm{Hg}>\mathrm{Pb}>\mathrm{Zn}>\mathrm{Cu}>\mathrm{Cr}>\mathrm{Ni}$.

EF values range between 5.9 (moderately severe EF; station M2) and 63.4 (extremely severe enrichment; station I4); Hg EF values range between 1.7 (minor enrichment; station M6) and 62.4 (extremely severe enrichment; station I4); Pb EF values range between 2.4 (minor enrichment; station M2) and 59 (extremely severe EF; station I4); Zn EF values range 

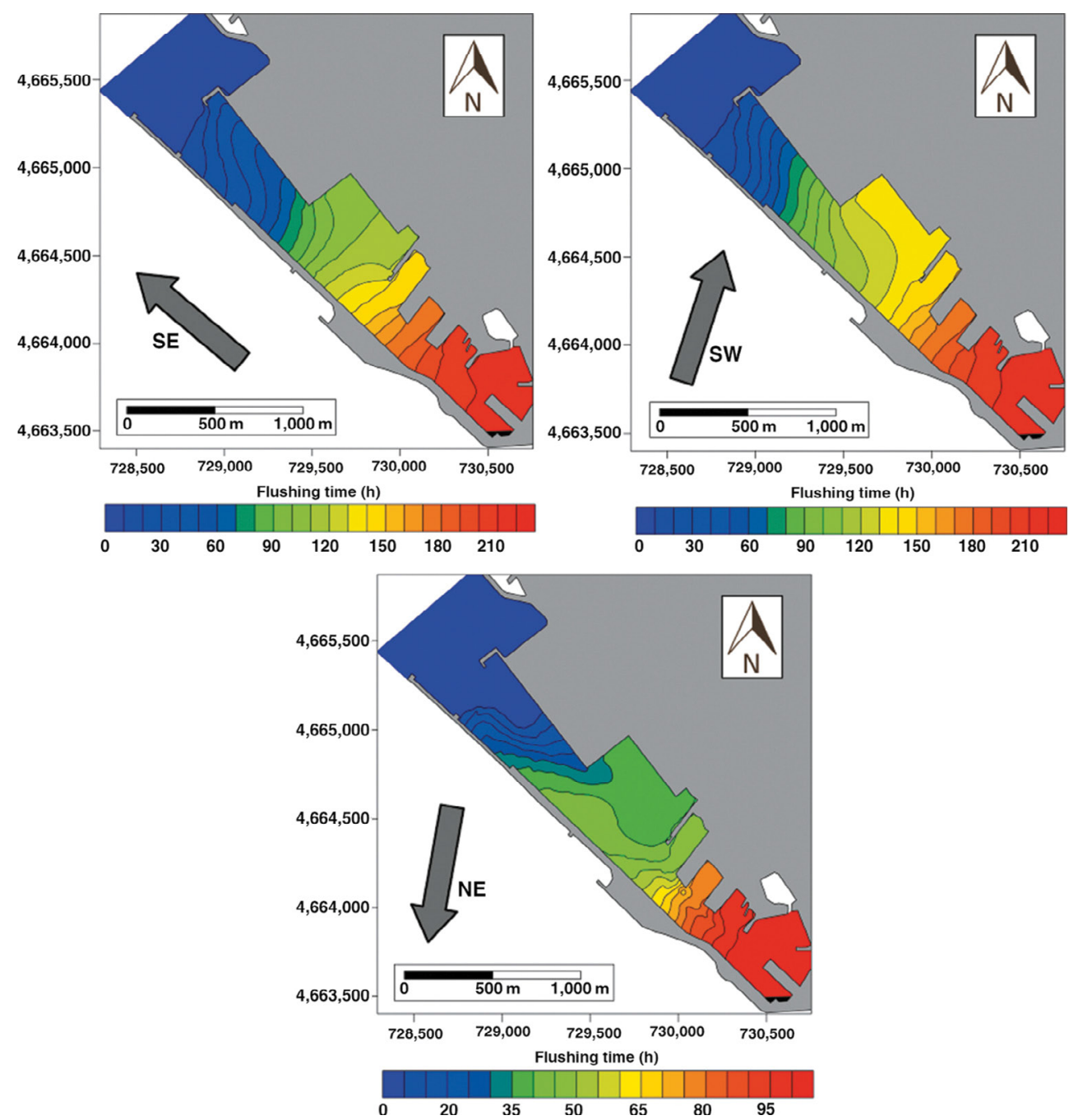

Figure 2: FT distribution of the idealized scenarios.

between 1.5 (minor enrichment; station M5) and 44.7 (very severe enrichment; station I4); $\mathrm{Cu}$ EF values range between 1.5 (minor enrichment; station M2) and 21.8 (severe enrichment; station I4); Cr EF values range between 0.1 (no enrichment; station M6) and 12 (severe enrichment; station I4); Ni EF values range between 0.4 (no enrichment; station M2) and 5.7 (moderately severe enrichment; station I4).

$\mathrm{EF}$ values of $\mathrm{As}, \mathrm{Cr}, \mathrm{Hg}, \mathrm{Ni}, \mathrm{Cu}, \mathrm{Zn}$ and $\mathrm{Pb}$ agree with the results reported by Piazzolla et al. [31]. In particular, As enrichment exhibited the highest values due to the overlap with the high natural As levels derived from local rivers and the intense human activities located in the surrounding area. 

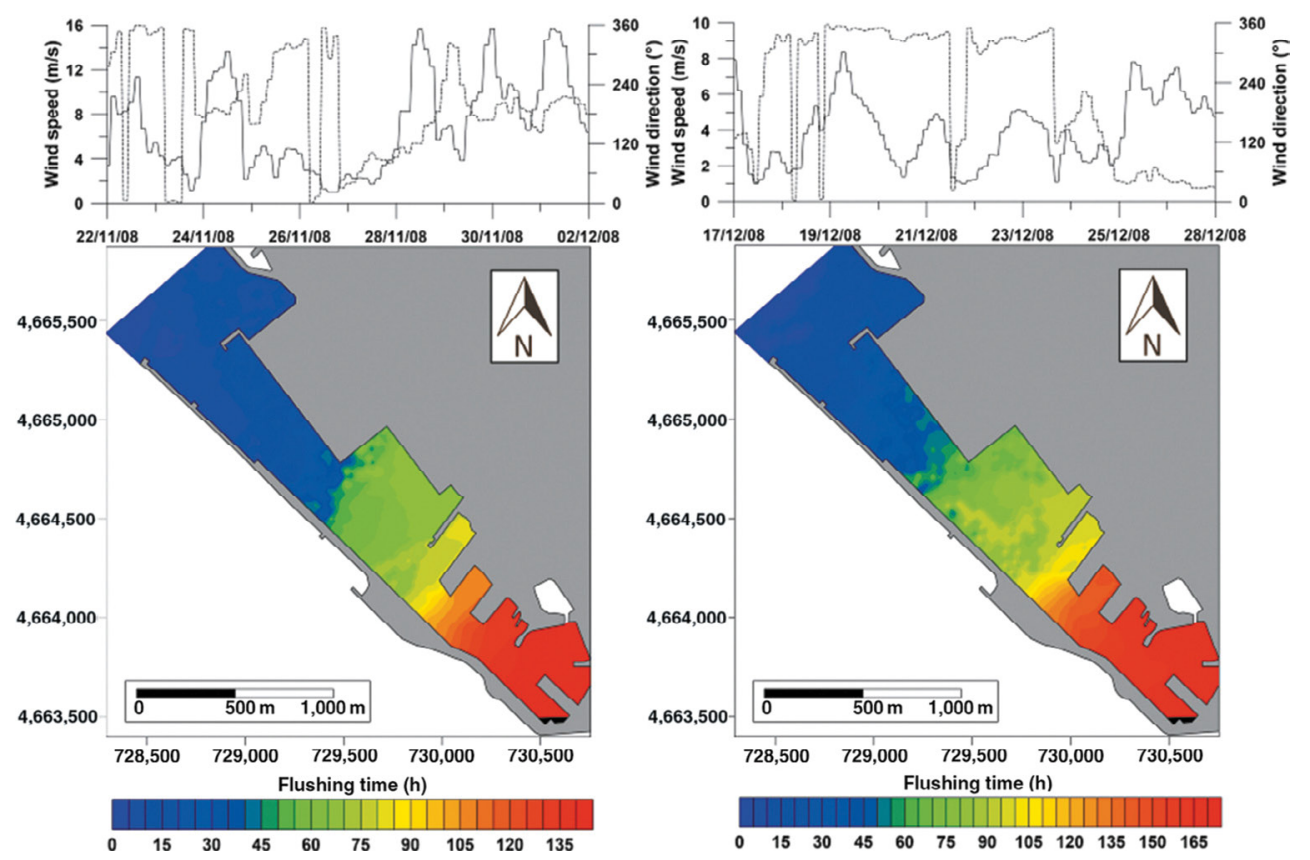

Figure 3: FT distribution of R1 (on the left) and R2 (on the right) scenarios calculated with the wind conditions showed at the top.

\subsection{Correlation analysis between FT and EF}

The results of Pearson's correlation performed between the enrichment degree of contaminants in marine sediments (EF) and water renewal time (FT) for all simulated scenarios are reported in Table 2.

Analysing the distribution of EF and FT values, it is evident that the correlation between two indices can be represented by a positive linear trend. This means that a higher water recirculation time corresponds to a higher contamination level in the marine sediments and vice versa.

Table 2: Results of Pearson's correlation analysis between trace metals EF values and FT in the idealized (I) and real (R) scenarios.

\begin{tabular}{lccrrrrrrrrr}
\hline & \multicolumn{2}{c}{ I-SE } & \multicolumn{2}{c}{ I-SW } & \multicolumn{2}{c}{ I-NE } & \multicolumn{2}{c}{ R1 } & \multicolumn{2}{c}{ R2 } \\
\cline { 2 - 11 } & $\mathbf{R}$ & $\boldsymbol{p}$-val & \multicolumn{1}{c}{$\mathbf{R}$} & $\boldsymbol{p}$-val & R & $\boldsymbol{p}$-val & $\mathbf{R}$ & $\boldsymbol{p}$-val & $\mathbf{R}$ & $\boldsymbol{p}$-val \\
\hline $\mathbf{E F}(\mathbf{A s})$ & 0.88 & $<0.001$ & 0.86 & $<0.001$ & 0.93 & $<0.001$ & 0.91 & $<0.001$ & 0.88 & $<0.001$ \\
$\mathbf{E F}(\mathbf{C r})$ & 0.91 & $<0.001$ & 0.91 & $<0.001$ & 0.91 & $<0.001$ & 0.93 & $<0.001$ & 0.90 & $<0.001$ \\
$\mathbf{E F}(\mathbf{H g})$ & 0.73 & 0.004 & 0.71 & 0.006 & 0.85 & $<0.001$ & 0.81 & $<0.001$ & 0.75 & 0.003 \\
$\mathbf{E F}(\mathbf{N i})$ & 0.96 & $<0.001$ & 0.96 & $<0.001$ & 0.94 & $<0.001$ & 0.95 & $<0.001$ & 0.96 & $<0.001$ \\
$\mathbf{E F}(\mathbf{P b})$ & 0.68 & 0.01 & 0.66 & 0.015 & 0.81 & $<0.001$ & 0.77 & $<0.001$ & 0.70 & 0.0077 \\
$\mathbf{E F}(\mathbf{C u})$ & 0.84 & $<0.001$ & 0.82 & $<0.001$ & 0.92 & $<0.001$ & 0.89 & $<0.001$ & 0.85 & $<0.001$ \\
$\mathbf{E F}(\mathbf{Z n})$ & 0.83 & $<0.001$ & 0.81 & $<0.001$ & 0.92 & $<0.001$ & 0.89 & $<0.001$ & 0.84 & $<0.001$ \\
\hline
\end{tabular}


The correlation coefficient is always greater than 0.67 , highlighting that a significant correspondence $(p$-val $<0.05)$ occurs between hydrodynamic and contamination index. In particular, all metal tracers show higher correlations in I-NE and R1 conditions and lower agreement in I-SE and I-SW scenarios. Among the trace metals, $\mathrm{Ni}$ and $\mathrm{Cr}$ show best correlations in all the considered scenarios.

\section{DISCUSSION AND CONCLUSION}

Although a marked difference exists in the wind intensity between R1 (maximum value of $8 \mathrm{~m} / \mathrm{s}$ ) and R2 (maximum value of $16 \mathrm{~m} / \mathrm{s}$ ) scenarios, a slight discrepancy occurs among the FT values between the two real conditions in the inner and central parts of Civitavecchia port. This means that the external current direction induced by wind conditions is the main factor regulating the inner harbour hydrodynamic and hence the water renewal time in this zone. A previous article [19] highlighted that the northward current outside the port produces a low circulation in the inner part of the harbour basin, while the southward external current directly influences the inner dynamic of Civitavecchia port, inducing higher velocity with respect to the previous case. The role of external current direction on the water exchange between the inner part of the port and the open sea is also confirmed by the FT lower values calculated in I-NE condition with respect to I-SE and I-SW ones.

Since this exchange rate is able to affect significantly the fate of contaminants within the harbour domain $[32,33]$, this study focused on the relation between EF of the metal tracer analysed in the harbour sediment and FT. The significant positive correlation between hydrodynamics and contamination index in semi-enclosed area suggests that high water renewal time increases the enrichment level of the considered elements in marine sediments allowing them more time to associate with suspended fine particles along the water column and then settle on the bottom. A further confirmation about the role of external current direction is given by the trace metal contamination in harbour basins, as high correlation results between EF values and FT calculated in I-NE scenario. The better fit of $\mathrm{Ni}$ and $\mathrm{Cr}$ probably reflects the influence caused by iron materials handling inside the harbour, providing a direct input of $\mathrm{Ni}$ and $\mathrm{Cr}$, hence explaining the largest $\mathrm{EF}$ values inside the harbour basin.

In conclusion, this study shows that FT can be used as a suitable indicator to determine the harbour zones particularly affected by trace metal contamination, and thus, the water quality degradation. Port managers could use this knowledge to take specific measures for each site, hence contributing effectively to maintain or achieve the GEP in the harbour areas.

Furthermore, the analysis of FT distribution is strongly recommended before defining a proper assessment survey of the port basin.

\section{ACKNOWLEDGEMENTS}

The authors wish to thank the Environmental Office of the Civitavecchia Port Authority for funding the study of the heavy metal contamination of the harbour surface sediments.

The article was also partly funded by the RITMARE project.

\section{REFERENCES}

[1] Grifoll, M., Jordà, G., Borja, A. \& Espino, M., A new risk assessment method for water quality degradation in harbour domains, using hydrodynamic models. Marine Pollution Bulletin, 60(1), pp. 69-78, 2010. DOI: 10.1016/j.marpolbul.2009.08.030.

[2] Mali, M., De Serio, F., Dell'Anna, M.M., Mastrorilli, P., Damiani, L. \& Mossa, M., Enhancing the performance of hazard indexes in assessing hot spots of harbour areas 
by considering hydrodynamic parameters. Ecological Indicators, 73, pp. 38-45, 2017. DOI: 10.1016/j.ecolind.2016.09.028.

[3] Jouon, A., Douillet, P., Ouillon, S. \& Fraunie, P., Calculations of hydrodynamic time parameters in a semi-opened coastal zone using a 3D hydrodynamic model. Continental Shelf Research, 26(12), pp. 1395-1415, 2006. DOI: 10.1016/j.csr.2005.11.014.

[4] Cucco, A. \& Umgiesser, G., Modeling the Venice Lagoon residence time. Ecological Modelling, 193(1), pp. 34-51, 2006. DOI: 10.1016/j.ecolmodel.2005.07.043.

[5] Torréton, J.P., Rochelle-Newall, E., Jouon, A., Faure, V., Jacquet, S. \& Douillet, P., Correspondence between the distribution of hydrodynamic time parameters and the distribution of biological and chemical variables in a semi-enclosed coral reef lagoon. Estuarine Coastal and Shelf Science, 74(4), pp. 766-776, 2007. DOI: 10.1016/ j.ecss.2007.05.018.

[6] Lisi, I., Taramelli, A., Di Risio, M., Cappucci, S. \& Gabellini, M., Flushing efficiency of Augusta Harbour (Italy). Journal of Coastal Research, 56, pp. 841-845, 2009.

[7] Grifoll, M., Jordà, G. \& Espino, M., Surface water renewal and mixing mechanisms in a semi-enclosed microtidal domain. The Barcelona harbour case. Journal of Sea Research, 90, pp. 54-63, 2014. DOI: 10.1016/j.seares.2014.02.007.

[8] Monsen, N.E., Cloern, J.E., Lucas, L.V. \& Monismith, S.G., A comment on the use of flushing time, residence time, and age as transport time scales. Limnology and Oceanography, 47(5), pp. 1545-1553, 2002. DOI: 10.4319/lo.2002.47.5.1545.

[9] Dunn, R.J.K., Teasdale, P.R., Warnken, J. \& Schleich, R.R., Evaluation of the diffusive gradient in a thin film technique for monitoring trace metal concentrations in estuarine waters. Environmental Science and Technology, 37(12), pp. 2794-2800, 2003. DOI: 10.1021/es026425y.

[10] Schintu, M., Durante, L., Maccioni, A., Meloni, P., Degetto, S. \& Contu, A., Measurement of environmental trace-metal levels in Mediterranean coastal areas with transplanted mussels and DGT techniques. Marine Pollution Bulletin, 57(6), pp. 832-837, 2008. DOI: 10.1016/j.marpolbul.2008.02.038.

[11] Warnken, K.W., Zhang, H. \& Davison, W., In situ monitoring and dynamic speciation measurements in solution using DGT comprehensive analytical chemistry. Passive Sampling Techniques in Environmental Monitoring, Vol. 48, eds. R. Greenwood, G. Mills \& B. Vrana, Elsevier: Amsterdam, pp. 251-278, 2007.

[12] Salomons, W. \& Forstner, U., Metals in the Hydrocycle, Springer: Berlin, pp. 349, 1984.

[13] Chase, Z., Paytan, A., Beck, A., Biller, D., Bruland, K., Measures, C. \& Sañudo-Wilhelmy, S., Evaluating the impact of atmospheric deposition on dissolved trace-metals in the Gulf of Aqaba, Red Sea. Marine Chemistry, 126(1), pp. 256-268, 2011. DOI: 10.1016/j.marchem.2011.06.005.

[14] Maanan, M., Saddik, M., Maanan, M., Chaibi, M., Assobhei, O. \& Zourarah, B., Environmental and ecological risk assessment of heavy metals in sediments of Nador lagoon, Morocco. Ecological Indicators, 48, pp. 616-626, 2015. DOI: 10.1016/j. ecolind.2014.09.034.

[15] Doering, P., Temporal variability of water quality in the St. Lucie estuary, South Florida. Water Resources Bulletin, 32(6), pp.1293-1306, 1996. DOI: 10.1016/B978-012-761890-6.50033-2.

[16] Mari, X., Rochelle-Newall, E., Torréton, J.P., Pringault, O., Jouon, A. \& Migon, C., Water residence time: A regulatory factor of the DOM to POM transfer efficiency. Limnology and Oceanography, 52(2), pp. 808-819, 2007. DOI: 10.4319/lo.2007.52.2.0808. 
[17] Migon, C., Ouillon, S., Mari, X. \& Nicolas, E., Geochemical and hydrodynamic constraints on the distribution of trace metal concentrations in the lagoon of Nouméa, New Caledonia. Estuarine Coastal and Shelf Science, 74(4), pp. 756-765, 2007. DOI: 10.1016/j.ecss.2007.05.048.

[18] Montero, N., Belzunce-Segarra, M.J., Del Campo, A., Garmendia, J.M., Ferrer, L., Larreta, J., Gonzales, M., Maidana, M.A. \& Espino, M., Integrative environmental assessment of the impact of Pasaia harbour activities on the Oiartzun estuary (southeastern Bay of Biscay). Journal of Marine Systems, 109, pp. S252-S260, 2013. DOI: 10.1016/j. jmarsys.2011.06.002.

[19] Zappalà, G., Piermattei, V., Madonia, A., Martellucci, R., Bonamano, S., Pierattini, A., Burgio, C. \& Marcelli, M., Assessment of environmental conditions in Civitavecchia (Rome, Italy) harbour. WIT Transactions on Ecology and the Environment, 182, pp. 271-282, 2014. DOI: 10.2495/WP140241.

[20] Bonamano, S., de Mendoza, F.P., Piermattei, V., Martellucci, R., Madonia, A., Gnisci, V., Mancini, E., Fersini, G., Burgio, C., Marcelli, M. \& Zappalà, G., Mathematical models supporting the monitoring of Civitavecchia harbour (Rome). WIT Transactions on Modelling and Simulation, 59, pp. 443-454, 2015. DOI: 10.2495/CMEM150401.

[21] Bonamano, S., Piermattei, V., Madonia, A., de Mendoza, F.P., Pierattini, A., Martellucci, R., Stefanì, C., Zappalà, G., Caruso, G. \& Marcelli, M., The Civitavecchia Coastal Environment Monitoring System (C-CEMS): A new tool to analyse the conflicts between coastal pressures and sensitivity areas. Ocean Science, 12(1), pp. 87-100, 2016. DOI: 10.1016/S0025-326X(03)00289-3.

[22] Lesser, G.R., Roelvink, J.A., van Kester, J.A.T.M. \& Stelling, G.S., Development and validation of a three dimensional morphological model. Coastal Engineering, 51(8), pp. 883-915, 2004. DOI: 10.1016/j.coastaleng.2004.07.014.

[23] Riddle, A.M. \& Lewis, R.E., Dispersion experiments in UK coastal waters. Estuarine Coastal and Shelf Science, 51(2), pp. 243-254, 2000. DOI: 10.1006/ecss.2000.0661.

[24] Sinex, S.A. \& Wright, D.A., Distribution of trace metals in the sediments and biota of Chesapeake Bay. Marine Pollution Bulletin, 19, pp. 425-431, 1988. DOI: 10.1016/0025326X(88)90397-9.

[25] Windom, H.L., Smith, R.G. Jr \& Rawlinson, C., Particulate trace metal composition and flux across the south eastern US continental shelf. Marine Chemistry, 27, pp. 283-297, 1989. DOI: 10.1016/0304-4203(89)90052-2.

[26] Din, T.B., Use of aluminum to normalize heavy metal data from estuarine and coastal sediments of straits of Melaka. Marine Pollution Bulletin, 24, pp. 484-491, 1992. DOI: 10.1016/0025-326X(92)90472-I.

[27] Woitke, P., Wellmitz, J., Helm, D., Kube, P., Lepom, P. \& Litheraty, P., Analysis and assessment of heavy metal pollution in suspended solids and sediments of the river Danube. Chemosphere, 51, pp. 633-642, 2003. DOI: 10.1016/S0045-6535(03)00217-0.

[28] Zhang, W., Feng, H., Chang, J., Qu, J., Xie, H. \& Yu, L., Heavy metal contamination in surface sediments of Yangtze River intertidal zone: an assessment from different indexes. Environmental Pollution, 157(5), pp. 1533-1543, 2009. DOI: 10.1016/j. envpol.2009.01.007.

[29] Turekian, K.K. \& Wedepohl, D.H., Distribution of the elements in some major units of the earths crust. Bulletin Geological Society of America, 72, pp. 175-192, 1961. DOI: 10.1130/0016-7606(1961)72[175:DOTEIS]2.0.CO;2. 
[30] Sakan, S.M., Djordjevic, D.S., Manojlovic, D.D. \& Polic, P.S., Assessment of heavy metal pollutants accumulation in the Tisza river sediments. Journal of Environmental Management, 90, pp. 3382-3390, 2009. DOI: 10.1016/j.jenvman.2009.05.013.

[31] Piazzolla, D., Scanu, S., Frattarelli, F.M., Mancini, E., Tiralongo, F., Brundo, M.V., Tibullo, D., Pecoraro, R., Copat, C., Ferrante, M. \& Marcelli, M., Trace-metal enrichment and pollution in coastal sediments in the northern Tyrrhenian Sea, Italy. Archives of Environmental Contamination and Toxicology, 69(4), pp. 470-481, 2015. DOI: 10.1016/j.marpolbul.2007.09.024.

[32] Wang, C.F., Hsu, M.-H. \& Kuo, A.Y., Residence time of the Danshuei River estuary, Taiwan. Estuarine Coastal and Shelf Science, 60, pp. 381-393, 2004. DOI: 10.1016/j. ecss.2004.01.013.

[33] Yuan, D., Lin, B. \& Falconer, R.A., A modelling study of residence time in a macrotidal estuary. Estuarine Coastal and Shelf Science, 71, pp. 401-411, 2007. DOI: 10.1016/ j.ecss.2006.08.023. 